\title{
Emergency hospital admissions and three-year survival of adults with and without cardiovascular surgery for congenital cardiac disease
}

\author{
Harald Kaemmerer, MD, VD \\ Sohrab Fratz, MD \\ Ulrike Bauer, $M D^{\mathrm{b}}$ \\ Erwin Oechslin, MD ${ }^{c}$ \\ Silke Brodherr-Heberlein, MD ${ }^{a}$ \\ Bernhard Zrenner, MD ${ }^{\mathrm{d}}$ \\ Juraj Turina, $\mathrm{MD}^{\mathrm{c}}$ \\ Rolf Jenni, MD ${ }^{c}$ \\ Peter E. Lange, $M D^{\mathrm{b}}$ \\ John Hess, MD ${ }^{a}$
}

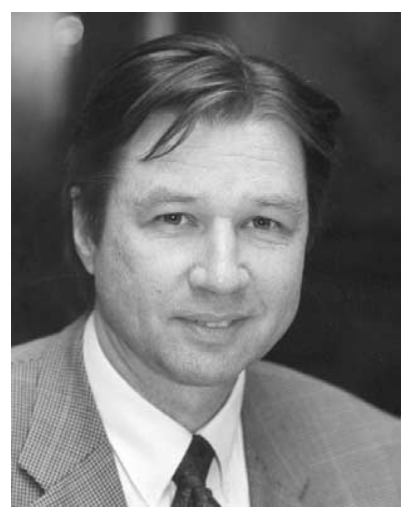

Dr Kaemmerer

\begin{abstract}
From the Department of Pediatric Cardiology and Congenital Heart Disease, ${ }^{\text {a }}$ Deutsches Hertzentrum München, Technische Universität München, München, Germany; Department of Congenital Heart Defects and Pediatric Cardiology, ${ }^{\mathrm{b}}$ Deutsches Hertzentrum Berlin, Berlin, Germany; Division of Cardiology, ${ }^{\mathrm{c}}$ University Hospital Zürich, Zürich, Switzerland; and Department of Cardiology, ${ }^{\mathrm{d}}$ Deutsches Hertzentrum München, Technische Universität München, München, Germany.

Received for publication Dec 19, 2002; revisions requested Jan 28, 2003; revisions received March 5, 2003; accepted for publication April 30, 2003.

Address for reprints: Harald Kaemmerer, MD, VD, Deutsches Hertzentrum München, Department of Pediatric Cardiology and Congenital Heart Disease, Lazarettstraße 36, D-80636 München, Germany (E-mail: Kaemmerer@dhm.mhn.de).

J Thorac Cardiovasc Surg 2003;126:1048-52

Copyright $\odot 2003$ by The American Association for Thoracic Surgery

$0022-5223 / 2003 \$ 30.00+0$

doi:10.1016/S0022-5223(03)00737-2
\end{abstract}

Objective: This study determined the quantity and nature of emergencies leading to unscheduled hospital admissions of adults with congenital cardiac disease and their mid-term survival.

Results: During 1 year, 429 adults with congenital cardiac diseases were admitted 571 times, and 124 admissions (22\%) of 95 patients (22\%) were emergency admissions. Fifteen of the 95 patients were seen for the first time in 1 of the participating centers. The underlying anomalies were Fallot's tetralogy and pulmonary atresia $(n=26 / 7)$, univentricular heart after Fontan procedure $(\mathrm{n}=25)$, atrial septal defect $(\mathrm{n}=18)$, Eisenmenger syndrome $(n=12)$, complete transposition $(n=11)$, and others $(n=25)$. Indications for admission were cardiovascular complications $(\mathrm{n}=103 ; 83 \%)$ (arrhythmia, cardiac failure, syncope, pacemaker problems, pericardial tamponade, and sudden death), infections ( $\mathrm{n}=8,6 \%$ ) (endocarditis, pacemaker infection, pneumonia, and cerebral abscess), acute chest pain $(n=7 ; 6 \%)$, and acute abdominal pain $(n=4 ; 3 \%)$. All patients required immediate emergency care, and 16 patients (17\%) required urgent cardiovascular or abdominal surgery. Six patients died during the hospital stay. During a follow-up of 2.9 years (SD 0.8), 16 (18\%) of the discharged patients died, and 2 additional patients underwent heart or heart-lung transplantation.

Conclusion: Adults with congenital cardiac disease often experience serious emergency situations with a high in-hospital and mid-term post-hospital mortality. Care given by physicians with special expertise is important in this specific group of patients.

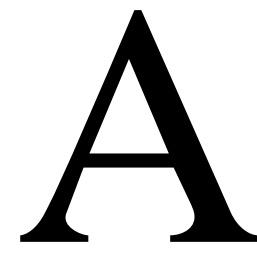

dvances in medicine and cardiac surgery have greatly improved the survival of children with congenital cardiac disease (CCD) ${ }^{1-5}$ This has resulted in a growing number of adults with CCD..$^{6-8}$ Because survival of children with CCD has increased from approximately $20 \%$ in the 1940 s to $85 \%$ in the new millennium, more than 35,000 and 5500 pediatric patients with CCD in the United States and Germany, respectively, will reach adulthood per year. ${ }^{9-11}$

During the spontaneous and the postoperative course, unscheduled hospital admissions resulting from residua and sequelae have to be anticipated. However, no data currently exist about the number and nature of these emergency hospital admissions. 
This multicenter study prospectively determined the quantity and nature of emergencies leading to unscheduled hospital admissions of adults with CCD to a supraregional referral center and their mid-term survival.

\section{Material and Methods}

During a 12-month period, 429 adults with CCD (age $<18$ years) admitted to 1 of 3 supraregional cardiologic tertiary care centers in Germany and Switzerland, specializing in adult CCD, were included. Ninety-five patients were admitted on an emergency basis.

Emergency was defined as any unscheduled hospital admission requiring immediate diagnostic work-up or treatment. Exclusion criteria were elective hospitalization, treatment as an outpatient, or patients aged less than 18 years with CCD.

Three years after inclusion, the outcome of all patients was evaluated. End points were defined as survival, death, heart transplantation, or heart-lung transplantation.

All gathered data and technical investigations were part of clinical follow-up. All patients or their guardians agreed to participate in the study.

StatView (Abacus Concepts, Inc, Berkeley, Calif) was used for statistical analysis. The results are presented as mean, SD, median, and range. The Kaplan-Meier method was used for survival analysis.

\section{Results}

Between January 1, 1998, and December 31, 1998, a total of 429 adults with CCD were admitted 571 times (some patients were admitted several times) to 1 of the participating centers. Of these, 124 admissions (22\%) were unscheduled in 95 patients $(22 \%)$. The mean age of the urgently admitted patients was 35.6 years (SD 14.3) (median 32.3 years; range 18-76 years).

The type of the underlying CCD is presented in Table 1. Repaired tetralogy of Fallot, atrial septal defects, univentricular circulation after Fontan operation, Eisenmenger syndrome, and transposition after atrial switch procedure accounted for $73 \%$ of all involved CCD.

Seventy patients $(74 \%)$ had undergone at least 1 heart operation for CCD, and 25 patients $(26 \%)$ had not undergone either cardiac surgery or catheter interventions.

Fifteen of the 95 patients were seen for the first time in 1 of the participating centers with the following underlying diagnoses: Eisenmenger syndrome $(n=5)$, Fallot's tetralogy $(\mathrm{n}=3)$, atrial septal defect $(\mathrm{n}=2)$, congenitally corrected transposition $(\mathrm{n}=2)$, complete transposition after atrial switch $(\mathrm{n}=1)$, aortic coarctation $(\mathrm{n}=1)$, and Marfan syndrome $(n=1)$. However, all 95 patients had been previously diagnosed and seen by a nonspecialized physician who diagnosed their conditions.

Tables 2 and 3 describe the primary reason leading to the unscheduled hospital admission. The majority of admissions $(\mathrm{n}=103 ; 83 \%)$ were the result of cardiovascular complications (Table 2).
TABLE 1. Nature of underlying congenital cardiac disease in the observed emergencies

\begin{tabular}{lcc}
\hline & Patients & Admissions \\
\hline Tetralogy of Fallot & 18 & 26 \\
Atrial septal defect & 17 & 18 \\
Status post-Fontan operation & 13 & 25 \\
Eisenmenger syndrome & 12 & 12 \\
Transposition of the great & 9 & 11 \\
$\quad$ arteries after atrial switch & 5 & 6 \\
Univentricular heart (non- & & \\
$\quad$ Fontan) & 4 & 4 \\
Aortic valve disease & 4 & 4 \\
Congenitally corrected & & \\
$\quad$ transposition & 3 & 3 \\
Aortic coarctation & 3 & 7 \\
Status postconduit & & \\
$\quad$ implantation (complex $\quad$ pulmonary atresia or & & \\
$\quad$ complete transposition) & & 2 \\
Ventricular septal defect & 2 & 1 \\
Marfan syndrome & 2 & 1 \\
Total anomalous pulmonary & 1 & 124 \\
$\quad$ venous return & & \\
M. Ebstein & 1 & \\
Atrioventricular septal defect & 1 & \\
Total & 95 & \\
\hline
\end{tabular}

Endocarditis was classified as infectious emergency, which formed with other infections the second largest group $(\mathrm{n}=8 ; 6 \%$; Table 3$)$. All other cases were related to acute pain, either typical noncardiac thoracic pain $(\mathrm{n}=7 ; 6 \%)$ or acute abdominal pain $(\mathrm{n}=4 ; 3 \%)$, a thromboembolic event, or a psychologic problem.

Arrhythmias were the most common reasons for admission in the cardiovascular group (66 admissions; 53\%). Arrhythmia-related admissions included patients with atrial fibrillation and flutter, supraventricular tachycardia, ventricular tachycardia, symptomatic bradycardia, and implantable cardioverter-defibrillator bursts (Table 2). Acute congestive heart failure (24 admissions; 19\%) was another common reason for immediate admission in the cardiovascular group. Sudden cardiac death, pacemaker problems, acute aortic dissection, pericardial tamponade, or cerebral ischemia were less frequent (Table 2).

Infectious reasons that led to an emergency admission could be attributed to endocarditis, pacemaker infections, pneumonia, and a cerebral abscess (Table 3).

The main indications in the subgroup of patients who presented for the first time were determined by cardiovascular complications $(\mathrm{n}=11)$ : cardiac failure in Eisenmenger syndrome $(n=2)$, Fallot's tetralogy $(n=1)$, and aortic coarctation $(n=1)$; supraventricular arrhythmia in atrial septal defect $(n=1)$, complete transposition $(n=1)$, and Fallot's tetralogy $(\mathrm{n}=1)$; ventricular arrhythmia in 
TABLE 2. Cardiovascular emergencies

\begin{tabular}{lcc}
\hline & Admissions & $\begin{array}{c}\text { Percentage of } \\
\text { total }\end{array}$ \\
\hline Arrhythmia & 66 & $53 \%$ \\
$\quad$ Supraventricular arrhythmias & 58 & $47 \%$ \\
$\quad$ Ventricular tachycardia & 4 & $3 \%$ \\
$\quad$ Symptomatic bradycardia & 3 & $2 \%$ \\
ICD burst & 1 & $1 \%$ \\
Acute congestive heart failure & 24 & $19 \%$ \\
Syncope & 3 & $2 \%$ \\
Cerebral ischemia & 3 & $2 \%$ \\
Pacemaker problems & 2 & $2 \%$ \\
Acute aortic dissection & 2 & $2 \%$ \\
Pericardial tamponade/effusion & 2 & $2 \%$ \\
Sudden cardiac death & 1 & $1 \%$ \\
Total & $103 / 124$ & $83 \%$ \\
\hline
\end{tabular}

Endocarditis is classified as infectious emergency. $I C D$, Implantable cardioverter-defibrillator.

\section{TABLE 3. Infectious emergencies}

\begin{tabular}{lcc}
\hline & Admissions & Percentage of total \\
\hline Endocarditis & 3 & $2 \%$ \\
Pacemaker electrode infection & 2 & $2 \%$ \\
Pneumonia/pleural effusion & 2 & $2 \%$ \\
Cerebral abscess & 1 & $1 \%$ \\
Total & $8 / 124$ & $6 \%$ \\
\hline
\end{tabular}

Fallot's tetralogy $(\mathrm{n}=1)$; syncope in congenitally corrected transposition $(\mathrm{n}=1)$; pacemaker problems in congenitally corrected transposition $(\mathrm{n}=1)$; and aortic dissection in Marfan syndrome $(\mathrm{n}=1)$.

Problems resulting from infections (endocarditis $[\mathrm{n}=1]$, cerebral abscess $[\mathrm{n}=1]$, and pneumonia $[\mathrm{n}=1]$ ) were seen in 3 patients with Eisenmenger syndrome. One patient with an atrial septal defect, who had not undergone operation, experienced acute chest pain.

Surgical treatment was required in 16 patients (17\% of patients, $13 \%$ of admissions). Cardiovascular surgery was performed in 13 patients (14\% of patients, $10 \%$ of admissions) and included replacement of the ascending aorta and the aortic valve after aortic dissection type A (Marfan syndrome), closure of an atrial septal defect, repair of aortic coarctation, conduit exchange, and ventricular septal defectclosure in infective endocarditis, and implantation or revision of a pacemaker or implantable cardioverter-defibrillator. Emergency abdominal surgery was performed in 3 patients (cholecystitis, hysterectomy, and therapeutic abortion).

The distance between the home address or the referring hospital and the supraregional center was 4 to $700 \mathrm{~km}$ (mean $178 \mathrm{~km}$ [SD 195]; median $70 \mathrm{~km}$ ).
Most patients ( $\mathrm{n}=118 ; 95 \%)$ admitted on an emergency basis were discharged in good and stable condition after 9 days (SD 11) (median 6 days; range 1-77 days).

Six patients (5\% of the admissions) died. The causes of death were clinically identified as sudden cardiac death (after atrial switch in complete transposition), endocarditis (repaired tetralogy of Fallot), early postoperative bleeding (pulmonary atresia), pneumonia (Eisenmenger syndrome), complications during general anesthesia (Eisenmenger syndrome), and cardiorespiratory failure (Eisenmenger syndrome).

Of the 15 patients who presented for the first time in 1 of the 3 centers, 2 patients with Eisenmenger syndrome died in the hospital.

All patients who were admitted on an emergency basis remained in a continuous follow-up of 1 of the centers. The follow-up period of the discharged patients $(n=89)$ was 2.9 years (SD 0.8). Sixteen (18\%) of the discharged patients died after 1.7 years (SD 1.1). One patient underwent heart transplantation 34 days after discharge, and 1 patient underwent heart-lung transplantation 2.5 years after discharge (Figure 1).

The causes of death were cardiogenic: Eisenmenger syndrome, $\mathrm{n}=5$; univentricular heart, $\mathrm{n}=2$; status postFontan operation, $\mathrm{n}=2$; status post-conduit operation in pulmonary atresia, $\mathrm{n}=1$; due to coarctation, $\mathrm{n}=1$; status post-atrial switch in complete transposition, $\mathrm{n}=1$; repaired tetralogy of Fallot, $\mathrm{n}=1$ ); aortic redissection (Marfansyndrome, $\mathrm{n}=1$ ); due to a malignancy (atrial septal defect, $\mathrm{n}=1$ ); and from unknown origin (ventricular septal defect, $\mathrm{n}=1)$.

\section{Discussion}

The number of adults with CCD is continuously increasing worldwide. At the beginning of the third millennium, the estimated number of adults with hemodynamically significant CCD is more than 900,000 in the United States, ${ }^{8}$ approximately 130,000 in Canada, ${ }^{12}$ and more than 120,000 in Germany. ${ }^{13}$ Because of sequelae and residua in most types of CCD, emergency situations have to be expected in the long-term course. ${ }^{11}$

For the first time, the current study (involving a large number of patients) shows that approximately one fourth of all admissions to a specialized adult CCD center are urgent and unscheduled. In addition, the wide spectrum of CCD affected by an emergency and the great variety of emergencies are shown. Patients in their postoperative course and without any previous cardiac surgery or catheter intervention were represented in this study. Repaired tetralogy of Fallot, univentricular hearts after Fontan operation, atrial switch procedures in complete transposition, Eisenmenger syndrome, and atrial septal defects currently necessitate 


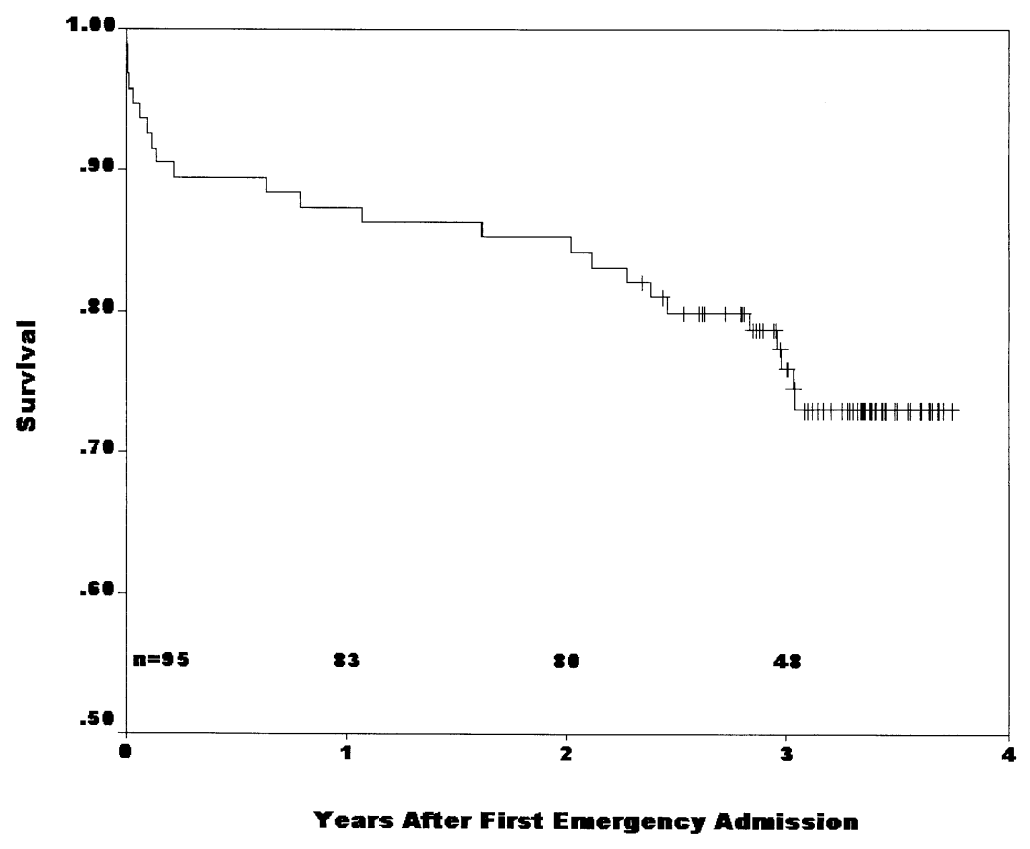

Figure 1. Survival function and time-to-event analysis (Kaplan-Meier curve) of all patients with congenital cardiac disease (CCD) discharged after emergency admission. End points were defined as death, heart transplant, or heart-Iung transplant.

emergency hospital admissions most often (63\% of patients, $74 \%$ of admissions).

The current study shows that most serious emergency problems concern atrial and ventricular arrhythmias, heart failure, sudden cardiac death, infections (including endocarditis and cerebral abscess), cerebral ischemia, and aortic dissections. In the context of CCD, these emergencies require specific expertise for an adequate diagnostic and therapeutic management.

Some of these emergency situations are similar to those associated with other cardiac diseases (eg, arrhythmias and aortic dissection), and little specific knowledge is needed for their primary management. However, a wider range of emergencies is typical for the underlying cardiac defect (eg, systemic ventricular failure after atrial switch procedure; thrombus formation, venous obstructions, or arrhythmias in patients who underwent the Fontan procedure; pulmonary affections in Eisenmenger syndrome, and cerebral abscess in cyanotic patients) requiring skilled approaches.

The wide variety of CCD and the different emergencies necessitate a broad diagnostic and therapeutic approach, exceeding the field of cardiology by far. Beyond basic cardiologic techniques, special diagnostic and therapeutic tools are needed, including sophisticated echocardiography and catheter techniques (angioplasty, valvuloplasty, shunt closure, and biopsy), electrophysiologic methodologies (pacing, mapping, and ablation), scintigraphy, and modern imaging techniques. ${ }^{14}$ Moreover, close affiliation to subspe- cialists (eg, in cardiac surgery, anesthesiology, nuclear medicine, radiology, obstetrics, neurology, neurosurgery, abdominal surgery, and internal medicine) taught to handle congenital heart problems is indispensable.

For an adequate, lifelong management of adults with CCD, especially in emergency situations, specialized physicians and centers and cooperation of all medical disciplines are required. ${ }^{15}$ Our study supports the recommendation of the 32 nd Bethesda conference ${ }^{16}$ concerning this, based on empirical data, with prospective data.

Moreover, it is essential to increase the number of physicians with sufficient knowledge and experience in the management of adults with complex anatomy and physiology. ${ }^{17}$ Even adult or pediatric cardiologists should have supplemental training in pediatric or adult cardiology, respectively, to deal with issues that do not belong in their traditional field.

The ever-increasing number of adults with CCD forces the creation of more specialized centers to manage longterm and emergency care of these chronically ill patients. At present, the scattered distribution of supraregional referral centers worldwide may imply unacceptable delays in adequate diagnostic and therapeutic interventions in emergency situations (in the current study home to hospital distances up to $700 \mathrm{~km}$ ), perhaps inducing a deleterious outcome.

Supraregional centers should cooperate with regional centers to manage adults with CCD more effectively ${ }^{6}$ and to identify trigger factors for emergency situations on the basis 
of large patient cohorts, developing guidelines for diagnosis, treatment, and follow-up. ${ }^{12,18}$

It has to be stressed that in the current study, $20 \%$ of all urgently admitted patients died or underwent heart or heartlung transplantation within 3 years after initial admission. This brings up the question of whether a closer and more structured follow-up of these patients could reduce the incidence of emergency admissions and influence the outcome. Further studies must address this question.

Finally, the case may be made for a well-designed national and regional registry for CCD with only a few centralized programs. The long-term results, including complications and life expectancy, warrant a more "prophylactic" approach to these patients through better and earlier inclusion into the medical system. Such a follow-up should include closely monitored protocols.

\section{Study Limitations}

This study was performed at tertiary care centers for adults with CCD. Thus, the sample of patients does not represent the typical population of adults with CCD seen by a general practitioner or cardiologist. The prevalence of cardiac emergencies in our institutions is likely to be higher than in regional hospitals or cardiology departments.

The observed patients may be a positive selection, because most were receiving regular follow-up in a specialized outpatient clinic for adults with CCD. Unfortunately, there is no comparator group of emergency outcomes in nonspecialized centers. Furthermore, no information exists regarding the number and kind of emergencies outside the referral center.

In addition, the study was too small to allow an assessment of gender differences and did not have long-term data regarding the cardiac status after the emergency.

\section{References}

1. Blalock A, Taussig HB. The surgical treatment of malformations of the heart in which there is pulmonary stenosis or pulmonary atresia. JAMA. 1945;128:189-202.

2. Fontan F, Baudet E. Surgical repair of tricuspid atresia. Thorax. 1971;26:240-8.

3. Lillehei CW, Cohen M, Warden HE, et al. Vision intracardiac surgical correction of the tetralogy of Fallot, pentalogy of Fallot, and pulmonary atresia defects. Ann Surg. 1955;142:418-42.

4. Mustard WT. Successful two-stage correction of transposition of the great vessels. Surgery. 1964;55:469.

5. Senning A. Surgical correction of transposition of the great vessels. Surgery. 1959;45:966-80.

6. Gatzoulis MA, Hechter S, Siu SC, et al. Outpatient clinics for adults with congenital heart disease: increasing workload and evolving patterns of referral. Heart. 1999;81:57-61.

7. Perloff JK. Congenital heart disease in adults. A new cardiovascular subspecialty. Circulation. 1991a;84:1881-90.

8. Perloff JK, Child JS. Congenital heart disease in adults. 2nd ed. Philadelphia: W.B. Saunders Company; 1998.

9. Moodie DS. Adult congenital heart disease. Curr Opin Cardiol. 1994; 137:42.

10. Perloff JK, Warnes CA. Challenges posed by adults with repaired congenital heart disease. Circulation. 2001;103:2637-43.

11. Webb GD. Care of adults with congenital heart disease-a challenge for the new millennium. Thorac Cardiovasc Surg. 2001;49:30-4.

12. Warnes CA, Liberthson R, Danielson GK, et al. Task force 1: the changing profile of congenital heart disease in adult life. J Am Coll Cardiol. 2001;37:1170-5.

13. Kaemmerer H, Muegge A, Lichtlen P, et al. Angeborene Herzfehler im Erwachsenenalter-eine neue Subdisziplin der Kardiologie. Herz Kreislauf. 1995;12:397-400.

14. Kaemmerer H, Stern HS, Fratz S, et al. Imaging in adults with congenital heart disease. Thorac Cardiovasc Surg. 2000;48:328-35.

15. Dore A, Glancy DL, Stone S, et al. Cardiac surgery for grown-up congenital heart patients: survey of 307 consecutive operations from 1991 to 1994. Am J Cardiol. 1997;80:906-13.

16. 32nd Bethesda Conference: care of the adult with congenital heart disease. J Am Coll Cardiol. 2001;37:1161-98.

17. Skorton DJ, Cheitlin MD, Freed MD, et al. Training in the care of adult patients with congenital heart disease. J Am Coll Cardiol. 1995;25:31-3.

18. Warnes A. Establishing an adult congenital heart disease clinic. Am J Card Imaging. 1995;9:11-4. 